\title{
Representações sociais do trabalho em um quadro de expectativa da primarização: um estudo em uma instituição de ensino superior
}

\section{(Social representations of work in an outsourcing reverse expectation context: a study in a higher education institution)}

\author{
Luiz Alex Silva Saraiva \\ lassaraiva@uol.com.br \\ Doutorando e Mestre em Administração pelo Centro de Pós-Graduação e Pesquisas em Administração da UFMG \\ Professor do Centro Universitário UNA
}

Silvana de Oliveira Faria Vianna silvana.faria@funcesi.br

Especialista em Gestão Empresarial e Bacharel em Administração pela Faculdade de Ciências Administrativas da Fundação Comunitária de Ensino Superior de Itabira FUNCESI

Editor Científico Responsável: Prof ${ }^{a}$. Dra. Karina de Déa Roglio Professora no Departamento de PPAD na Pontifícia Universidade Católica do Paraná

\begin{abstract}
Resumo
Neste artigo analisa-se a influência da expectativa de primarização sobre as representações sociais do trabalho em uma instituição de ensino superior mineira. Foi conduzido um estudo qualitativo baseado em entrevistas semiestruturadas com profissionais das áreas de vigilância e limpeza de uma empresa que prestava serviço à instituição de ensino superior, em um momento que precedeu a sua primarização, material examinado por meio da análise francesa de discurso (BAKHTIN, 2006; FIORIN, 2003). Os principais resultados indicam que as representações do processo são muito positivas, processo do qual os entrevistados esperavam se beneficiar diretamente, em termos profissionais e simbólicos, e indiretamente pelas oportunidades para suas famílias, principalmente para seus filhos. Pelo elevado nível de expectativas, é provável que os empregados se frustrem, o que influenciará suas representações sociais e desempenho no trabalho, algo considerado menos importante em termos de estratégia organizacional, que se aproxima ora da terceirização, ora da primarização.
\end{abstract}

Palavras-chave: Representações sociais. Trabalho. Primarização.

\begin{abstract}
In this paper we analyze the influence of re-insourcing expectations on social representations of work in a Minas Gerais' higher education institution. We have interviewed, through a qualitative semi-structured script, professionals of the vigilance and cleaning areas from university's outsourced company in a moment just before their hiring by university, data that were treated with the help of discourse analysis. Main results indicate that representations of this process were very positive, because interviewed ones hoped for professional and symbolical improvements to themselves, and also opportunities to their families, mainly to their children. It is probable that the employees frustrate themselves, what possibly will influence their social representations and performance at work. But apparently this is not so important in an organization that balances between outsourcing and re-insourcing strategies.
\end{abstract}

Key word: Social representations. Work. Re-insourcing. 


\section{INTRODUÇÃO}

A crescente competição observada há algum tempo levou a que consolidasse uma espécie de discurso único nas organizações a respeito da necessidade de se tornarem mais competitivas. A ideia básica de tal discurso é que a escassez de recursos, associada ao aumento da competição, exige a adoção de medidas racionalizadoras, que garantam resultados melhores e, consequentemente, a sobrevivência da organização. Festejada como uma das grandes ferramentas para fazer frente aos desafios da competição, a terceirização foi largamente usada como sinônimo de maior agilidade no processo produtivo. Uma vez que empresas especializadas passaram a desempenhar parte do que estava sob execução da contratante, esta tem espaço para desenvolver competência em atividades de maior valor agregado, tornando suas atividades teoricamente mais lucrativas pelo desenvolvimento de competências centrais em seus negócios (core business).

As empresas que tomam a decisão estratégica de terceirizar parte de suas atividades muitas vezes conseguem agregar mais valor a seu produto ou serviço do que companhias que não o fazem. Isso ocorre porque a terceirização, em alguns casos, incrementa a qualidade e melhora a operacionalidade, facilitando a administração de finanças, pessoal e estrutura e possibilitando novos investimentos. A efetivação das vantagens da terceirização, contudo, depende de uma combinação de fatores, que vão de uma conjuntura econômica favorável, a um maior ou menor grau de eficiência do processo de confiabilidade do fornecedor ou prestador de serviços, pois os setores a serem terceirizados não podem comprometer as funções estratégicas da empresa. Muitos processos de terceirização são mal sucedidos em virtude de problemas diversos, que têm origem em uma visão de competição mais do que de parceria entre as empresas envolvidas (DRUCK, 2001), na qual a parte mais forte impõe condições contratuais precárias para a outra parte, mais fraca. Esta, por sua vez, repassa as condições desfavoráveis para seus próprios empregados mediante elevadas jornadas de trabalho, baixos níveis de remuneração e, principalmente, incerteza de permanência no emprego.

Tal política tem reflexos diretos sobre os níveis de qualidade e de produtividade das empresas contratantes, que se veem ganhando muito na negociação contratual, mas perdendo muito também nos custos de retrabalho e na duplicação de controles (DRUCK; FRANCO, 2007). Diante desse contexto, muitas empresas tomam a decisão de fazer o processo inverso, investindo na primarização (re-insourcing), ou seja, assumindo todas as suas atividades até 
então terceirizadas, inserindo a mão-de-obra terceirizada em seu quadro funcional, de forma que esses continuem a executar os serviços, mas sob sua administração direta. Essa aproximação tem como objetivo principal concentrar maior confiabilidade, competência e comprometimento no negócio (CAPUTO; PALUMBO, 2005).

Para compreensão desse processo ainda pouco estudado no Brasil, foi conduzida uma pesquisa qualitativa embasada na teoria das representações sociais. O estudo das representações permite compreender as teorias do senso comum e o conjunto de significados atribuídos por um grupo social a um objeto, bem como os comportamentos a ele relacionados. O conceito de representações sociais apresenta-se como central neste estudo à medida que pressupõe uma forma específica de saber (o conhecimento comum), via de acesso a uma faceta psicossocial, sobre como a expectativa de primarização influencia as representações sociais dos empregados terceirizados sobre o trabalho, o principal objetivo do estudo.

Nas próximas seções, será apresentado o referencial teórico em relação às representações sociais e às possibilidades de significação do trabalho. Em seguida, discute-se a metodologia adotada na pesquisa, que precede à análise das entrevistas. A análise das entrevistas se subdivide em cinco percursos semânticos: o trabalho; o ambiente profissional; as expectativas quanto à primarização; as oportunidades de crescimento profissional e pessoal; e as alterações no significado do trabalho com a primarização, cuja discussão precede as considerações finais.

\section{AS REPRESENTAÇÕES SOCIAIS E O MUNDO DAS ORGANIZAÇÕES}

De acordo com Durkheim (1982, p.66), "nada ou quase nada escapa das configurações sociais, a sociedade age sobre os seus indivíduos independentemente da vontade destes". Essa ideia sustenta sua visão de representações coletivas, de que os indivíduos são conduzidos, em suas escolhas, por um pensamento social que a eles se sobrepõe inexoravelmente. Moscovici (1984) considera que o conceito de representações coletivas de Durkheim apresenta pontos falhos que não permitem a explicação de novos acontecimentos, indicando uma concepção pouco flexível sobre o indivíduo, sobre o que ele pensa, sente e fala. Dessa forma, ele se apropriou do conceito, modificando-o e utilizando-o em uma nova perspectiva de pesquisa - a das representações sociais. A visão de Durkheim é mais apropriada para um contexto de sociedades menos complexas, enquanto o de Moscovici se volta para as sociedades modernas, 
caracterizadas por seu pluralismo e pela rapidez com que as mudanças econômicas, políticas e culturais ocorrem (FARR, 1994). O que se nota é que o "social” de Moscovici, diferentemente do "coletivo" de Durkheim, designa o aspecto dinâmico e a bilateralidade no processo de constituição das representações sociais identificando duas facetas: por um lado, a representação como forma de conhecimento socialmente elaborado e partilhado, e, por outro, sua realidade psicológica e analógica inserida no comportamento do indivíduo.

As representações são medidas sociais da realidade, sendo produto e processo de uma atividade de elaboração psicológica e social dessa realidade nos processos de interação social (JODELET, 1986). A partir de Moscovici (1978), o caráter social das representações transparece na função específica que elas desempenham na sociedade, o de contribuir para os processos de formação de condutas e de orientação das comunicações sociais (REIGOTA, 1995). De acordo com Spink (1995), o conceito de representações coletivas, no entender de Moscovici, continha vários aspectos que o impediram de dar conta dos novos fenômenos detectados.

Ao contrário dos modelos psicossociológicos que costumam encarar o tratamento de informação como um processo sobretudo individual, Moscovici a situa no interior de grupos e da sociedade, sem os quais não se podem compreender adequadamente os processos de circulação da informação, porque para ele não há um corte dado entre o universo exterior e o universo do indivíduo, chamando atenção para a inter-relação entre o sujeito e não sujeito, e sujeito e outro sujeito (MOSCOVICI, 1978). Para Magnani (1986), a representação é algo assim como uma espécie de imagem mental da realidade. Os ingredientes dessa imagem seriam, em primeiro lugar, as experiências individuais decorrentes da realidade social em que o ator está imerso, realidade que se apresenta sob forma de círculos concêntricos: família, rede de vizinhança, bairro, categoria profissional, partido, classe social.

Embora as representações sociais constituam formas de conhecimento socialmente elaboradas, produzidas pelos grupos de indivíduos para poderem se comunicar e entender o que lhe é estranho e não familiar, nem todos os assuntos se tornam objeto de representação social para os grupos, e nem todos os fenômenos que rodeiam o indivíduo se convertem em problemas de pesquisa científica da representação social. Segundo Herzlich (1991), a noção de representação social de Moscovici é uma tentativa de tratar a influência recíproca da estrutura social e a do sujeito. Sua ênfase, porém, tendeu mais para este lado: a reflexão se apoiava mais no sujeito ativo, construtor do mundo a partir dos materiais que a sociedade lhe fornece, do que na própria estrutura social. Dessa forma, o conceito de representação social permite explicar o lugar que ocupa a representação nas sociedades pensantes. 
A mobilização de tais representações sociais acontece, assim, em todas as ocasiões e lugares onde as pessoas se encontram formal e informalmente e se comunicam. As representações sociais, por seu poder convencional e prescritivo - já que se baseiam em ajustamentos sociais mútuos e indicam o que é mais adequado a ser feito em cada situação sobre a realidade, terminam por constituir o pensamento em um ambiente em que se desenvolve a vida cotidiana (MOSCOVICI, 1984). O conhecimento é gerado pela compreensão alcançada por indivíduos que pensam, mas não sozinhos, e a semelhança de seus pronunciamentos com os de outros grupos de que participam demonstra que, em alguma medida, terão pensado juntos sobre os mesmos assuntos. E é isso que se entende por uma explicação psicossociológica da origem dessa forma de pensamento, que Moscovici denominou Representações Sociais.

Para Moscovici (1995), a externalidade das representações e de seu processo aos olhos dos sujeitos, seu deslocamento, sua naturalização e projeção consistem num mecanismo psicossocial de apresentação/construção social da realidade. As representações, uma vez constituídas, não se convertem necessariamente em leis de funcionamento social. O elemento "construção" assume um lugar central, representando o esforço de trazer o indivíduo a seu lugar de sujeito na medida em que o percebe em sua condição de socialmente constituído e, ao mesmo tempo, constituinte. Dentro desse contexto, torna-se importante conhecer os processos formadores das representações sociais, a saber: ancoragem ${ }^{1}$ e objetivação ${ }^{2}$. Objetivar, assim, é reabsorver um excesso de significações, materializando e trazendo para o universo vivido o que antes era palavra ou símbolo. Representar, no entanto, não significa reproduzir ou duplicar, significa construir, ou seja, participar ativamente do processo de construção da sociedade e de si. A teoria das representações devolve ao indivíduo sua importância na formação social e afirma sua participação ativa nesse processo.

As representações sociais são um sistema de interpretação da realidade, que organiza as relações do indivíduo com o mundo, orientando suas condutas e comportamentos no meio social, o que lhe permite interiorizar as experiências, as práticas sociais e os modelos de conduta, ao mesmo tempo em que constrói e se apropria de objetos socializados (XAVIER, 2002). Desse modo, a relevância sociológica do estudo das representações sociais está no fato de que elas fundamentam práticas e atitudes dos sujeitos, uns em relação aos outros, ao contexto social e àquilo que lhes acontece. Assim, as representações sociais equivalem a um

\footnotetext{
${ }^{1}$ A ancoragem consiste na integração cognitiva do objeto representado, sejam ideias, acontecimentos, pessoas e relações a um sistema de pensamento social preexistente e nas transformações implicadas (JODELET, 1986).

22 Já a objetivação consiste em transformar uma abstração em algo material. Para Moscovici (1984), objetivar é descobrir a qualidade icônica de uma ideia ou ser imprecisos, reproduzir um conceito em uma imagem.
} 
conjunto de princípios construídos interativamente e compartilhados por diferentes grupos que, por meio delas, compreendem e transformam sua realidade. Elas organizam as condutas e as comunicações sociais e intervêm na difusão e na assimilação dos conhecimentos, além de participar na definição das identidades pessoais e sociais.

As representações sociais podem ser definidas como senso comum, imagens, concepções e visão de mundo que os atores sociais possuem da realidade (MINAYO, 1999). Essas representações se compõem de figuras e expressões socializadas, frutos da vivência das contradições que permeiam o dia-a-dia dos indivíduos dos diferentes estratos sociais. São também resultados do conteúdo psíquico, da individualidade de cada um, que interpreta figuras e expressões socializadas segundo seu próprio potencial. São ao mesmo tempo ilusórias, contraditórias, verdadeiras e matéria-prima para análise social. As representações sociais não são, portanto, respostas que um indivíduo emite em relação a algum acontecimento social, mas as maneiras como os grupos sociais organizam e constroem os diferentes significados dos estímulos do meio social e as possibilidades de respostas que podem acompanhar esses estímulos. Além disso, para Moscovici (1978), as representações são referências que circulam, cruzam-se e se cristalizam incessantemente por meio da fala, do gesto, dos encontros no universo cotidiano. Adotar o conceito de representações sociais significa, portanto, buscar compreender não somente o que e como as pessoas representam um objeto cujo conteúdo possui um valor socialmente evidente e relevante, mas também por que e para que o fazem daquela forma.

As representações sociais são responsáveis por dar significado e coerência ao universo vivido e expressam-se em várias formas de comunicação, servindo assim como pano de fundo para as atividades dos indivíduos. O estudo das representações permite compreender o conjunto de significados atribuídos por um determinado grupo social a um objeto, bem como aos comportamentos relativos a esses objetos. Embora existam múltiplos conceitos e delineamentos metodológicos das representações sociais, definidos pelo próprio Moscovici (1981), não se pode considerá-las uma teoria acabada, mas como uma ampla abordagem inovadora no campo da psicologia social. Essa abordagem tem sido criticada, seja com relação à falta de precisão conceitual, pois Moscovici não apresentou um conceito definitivo, seja no que se refere à debilidade dos procedimentos metodológicos empregados nos estudos orientados para essa abordagem, já que, conforme Oliveira e Werba (1998), não existe uma metodologia exclusiva para a investigação das representações sociais, havendo desde procedimentos quantitativos a abordagens qualitativas. Além disso, como apontam Eslava Albarracín e Almeida (2002), por seu caráter social, as representações sociais tanto podem 
servir de suporte para as ideologias dominantes, quanto para facilitar a institucionalização de algumas práticas sociais.

Mesmo diante dessas restrições, as representações sociais constituem um campo vasto de pesquisa, pois têm a capacidade de englobar uma ampla variedade de temas, visto que se relacionam a qualquer objeto social, que é transmitido através da comunicação e que tenha importância para o grupo, fazendo parte de suas práticas cotidianas. De acordo com Campos (2001), a teoria das representações constitui um importante meio - particularmente, nas situações em que os aspectos simbólicos são determinantes das condutas - das práticas e dos comportamentos dos grupos sociais. Além do mais, conforme Santos, Novelino e Nascimento. (2001), as representações têm, entre outras, a função de nortear as pessoas em seu ambiente, servindo de guias referenciais de ação. Ao estudar as representações sociais de um grupo acerca de um objeto qualquer, é necessário conhecer a história social e conhecer o contexto em que grupo está inserido. Um desses contextos diz respeito ao trabalho abordado na próxima seção.

\section{O TRABALHO E SUAS POSSIBILIDADES DE SIGNIFICAÇÃO}

$\mathrm{Na}$ linguagem cotidiana, a palavra trabalho tem muitos significados. Às vezes, carregada de emoção, lembra dor, tortura, suor no rosto, fadiga. Em outras, mais que aflição e fardo, designa a operação humana de transformação da matéria natural em objeto de cultura, de acordo com Albornoz (1986). Para outros autores, como Carmo (1997), o trabalho é a chave para superar os infortúnios e o parâmetro para medir a acumulação de capital, evidenciando a habilidade de "vencer a vida". Os donos de grandes fortunas passam a ter a ideia de que toda riqueza é montada à custa de grande disposição para o trabalho. Segundo Kupstas (1997), o homem se faz pelo trabalho, ou seja, ao mesmo tempo em que produz coisas, torna-se humano, constrói a própria subjetividade. À medida que trabalha, acumula experiência e sente prazer em fazer com facilidade o que antes the parecia um desafio intransponível. Outros autores, como Morin (2001), encaram-no como um valor importante, que influencia consideravelmente a motivação, a satisfação e a produtividade dos trabalhadores.

A história do trabalho começa quando o homem busca os meios para satisfazer suas necessidades. Essa busca se reproduz em toda a ação humana para que o homem possa 
continuar sobrevivendo. Trabalho, dessa forma, é uma relação de dupla transformação entre o homem e a natureza, isto é, trata-se do ato de transmitir significado à natureza, de transformála e utilizá-la para uma determinada finalidade, conforme Oliveira (1995). Para Carmo (1997), no trabalho, como toda a atividade realizada pelo homem civilizado que transforma a natureza pela inteligência, há mediação entre o homem e a natureza: submetendo-a ele a seu desejo, visa a extrair dela sua subsistência. Realizando essa atividade, o homem se transforma, se autoproduz e, ao se relacionar com outros homens, na realização da atividade, estabelece relações sociais.

À medida que a satisfação é atingida, ampliam-se as necessidades a outros homens e criam-se relações sociais que determinam a condição histórica do trabalho, conforme Oliveira (1995). Historicamente, o trabalho é associado a determinadas formas sociais, como escravismo, feudalismo e capitalismo, em que se tecem as relações que dominam o processo de trabalho. Esse processo é o resultado da combinação do objeto, dos meios, da força e do produto do trabalho. O trabalho, dessa forma, apresenta-se em vários estágios: no primeiro estágio da economia isolada e extrativa, é um esforço complementar ao trabalho da natureza o homem colhe o fruto produzido pela árvore e mata virgem. Como estágio consecutivo, temse o tempo em que os homens inventaram e descobriram a agricultura. Junto com o trabalho do plantio, devem ter surgido, ao mesmo tempo, a noção de propriedade e o produto excedente. Dentro desse contexto, acontece a prática da guerra. O povo conquistado na guerra frequentemente permanecia para trabalhar e entregar seus excedentes aos novos senhores ou então servia de força de trabalho (ALBORNOZ, 1986).

A partir da revolução industrial, o trabalho assume um novo significado, pois não se tratou apenas de emprego da máquina na produção, substituindo o trabalho manual. $\mathrm{O}$ expressivo crescimento da produção eliminou logo as formas anteriores de apropriação do trabalho, e tal apropriação passa para o burguês capitalista, fazendo da força de trabalho mercadoria; o trabalho é apropriado pelo dinheiro, o que Fromm (1983) denomina de preço do trabalho. O trabalhador torna-se apêndice da máquina e sua capacidade produtiva condicionase à noção de lucro, estabelecendo o domínio do trabalho pelo capital e a mais-valia, que, segundo Oliveira (1995), é a diferença entre o que o trabalhador recebe para produzir e o que ele efetivamente produz. Já que ele produz mais do que ganha, torna-se a marca registrada dessa dominação, pois sua extração gera lucro ao capitalista, uma vez que ela representa tempo extra de trabalho não remunerado.

De acordo com Saraiva e Provinciali (2002), a Revolução Industrial produziu consequências que alteraram profundamente a estrutura da sociedade ocidental capitalista, 
especialmente a organização empresarial, no que se refere ao desenvolvimento de princípios baseados na separação entre o trabalho mental e físico na execução da tarefa. A organização taylorista do processo de trabalho significou uma drástica redução da autonomia e da iniciativa do operário no âmbito da produção, tendo sua lógica conduzido os trabalhadores à execução de um trabalho extremamente fragmentado, repetitivo e monótono, definido pela gerência. $\mathrm{O}$ efeito direto da aplicação desses princípios foi a configuração de uma nova força de trabalho marcada pela perda das competências genéricas e um aumento brutal da produtividade.

Quando rotinizado e despersonalizado, o trabalho pode levar o homem a se sentir alheio àquilo que produz. Albornoz (1986) afirma que o trabalho passa a ser alienado do trabalhador porque o produtor não detém, não possui e nem domina os meios da produção. Vivendo no universo da mercadoria, o trabalhador também se torna mercadoria, distanciandose dos outros homens e até de si mesmo. A perda da autonomia em suas atividades faz com que ele não se reconheça mais como responsável pelo produto do trabalho realizado. Segundo Fromm (1983), o homem se aliena, ou seja, vende sua força de trabalho a outrem, a quem ele outorga e a quem passa a pertencer seu trabalho e o produto deste - ambos igualmente alienados. Assim, essa relação alienada do homem com seu trabalho e produto gera uma relação correspondente do capitalista com o trabalho, que é propriedade privada. Esta deriva da alienação do trabalho.

Se a propriedade dos meios de produção e do que é produzido levam à alienação, o mesmo se pode dizer de um sistema com suas "imposições de um poder [...] que decide pelo trabalhador, [e que] fazem do trabalho o dominador da natureza e da natureza humana" (CARMO, 1997, p.16). De acordo com Saraiva e Provinciali (2002), a alienação é uma das mais perversas consequências trazidas pelo taylorismo ao trabalhador, pois, quando o trabalho passou a ter um caráter intrínseco, segundo o qual quanto mais exaustiva sua natureza, maior o valor do trabalhador, o capitalismo encontrou condições extremamente favoráveis para a disseminação de seus valores. Percebe-se que, com a intensificação do ritmo do trabalho que se instalou em todos os ramos de atividades, não são as pessoas saudáveis e satisfeitas as mais úteis para o sistema e sim aquelas neuróticas e infelizes (LIMA, 1988). Quanto mais o trabalho é especializado, maior é sua alienação, pois elas tendem a se isolar do ambiente que as circunda.

Deve-se ter em mente, assim, que, ainda que uma base produtiva concreta sustente as configurações do trabalho, existe todo um sistema ideológico que confere sentido, e mesmo legitimidade, às formas atualmente observadas de exploração. Assim, não é incomum 
encontrar trabalhadores que se sentem satisfeitos precisamente em serem explorados por contribuírem para que uma ética do trabalho se mantenha, valorizando os que se submetem ao sistema sem maiores questionamentos (SARAIVA; SILVEIRA, 2007). O processo de trabalho, assim, vai além das atividades laborais propriamente ditas, incluindo as representações sociais dos trabalhadores a respeito do trabalho, o que possui implicações diversas, conforme a pesquisa realizada identificou, cujos procedimentos metodológicos são apresentados a seguir.

\section{METODOLOGIA}

$\mathrm{Na}$ presente pesquisa teve-se como objetivo identificar de que forma a expectativa da primarização influencia as representações sociais de empregados terceirizados sobre o trabalho. Para um descortinamento da subjetividade dos empregados terceirizados em relação à representação, a pesquisa qualitativa mostra ser a mais adequada, pois trabalha com o universo de significados, motivos, aspirações, crenças, valores e atitudes, o que corresponde a um espaço mais profundo das relações, dos processos e dos fenômenos que não podem ser reduzidos à operacionalização de variáveis, conforme Minayo (1996). A pesquisa, basicamente descritiva, foi feita em uma organização com atividades terceirizadas e em que a primarização havia sido anunciada.

Compuseram o universo 39 empregados que prestavam, na época, serviços nas áreas de limpeza e vigilância da Faculdade ${ }^{3}$. A amostra do tipo não-probabilística baseou-se no critério de acessibilidade para a escolha dos sujeitos entrevistados. Embora os 39 trabalhassem na organização na época da coleta de dados, alguns tinham horários restritivos, incompatíveis com os dos pesquisadores, e outros se mostraram, após um primeiro contato, pouco receptivos. Os sujeitos selecionados para a pesquisa, em número de 8 , demonstraram, ao mesmo tempo, interesse, abertura e disponibilidade para participar das entrevistas. A coleta de dados primários foi efetuada mediante um roteiro de entrevista semiestruturada, composto de questões abertas, que visavam captar pela observação e pela fala os aspectos ligados à problemática central. As entrevistas foram integralmente gravadas e transcritas como meio de assegurar maior fidedignidade do material coletado.

\footnotetext{
${ }^{33}$ Nome fictício para a organização estudada. 
As entrevistas foram realizadas no próprio campus da Faculdade entre os meses de outubro e novembro de 2006, em um período que precedeu o processo de primarização, que só veio a ocorrer em fevereiro do ano seguinte. Era oportuna a realização dessa pesquisa nesse período, tendo em vista que o foco do estudo era analisar como a expectativa desse processo alteraria as representações sociais sobre o trabalho. Supôs-se que os terceirizados, com a expectativa da primarização, assumissem uma nova visão do que é trabalho, com diversos efeitos sobre seu desempenho. O material coletado foi tratado com base na análise de discurso, um conjunto sistemático de procedimentos para o tratamento de textos diversos (BAKHTIN, 2006). O principal procedimento adotado, além da análise dos aspectos explícitos, implícitos e silenciados, foi a identificação de percursos semânticos (MAINGUENEAU, 1998), tendo sido identificados cinco percursos semânticos principais: o trabalho; o ambiente profissional; as expectativas quanto à primarização; as oportunidades de crescimento profissional e pessoal; e as alterações no significado do trabalho com a primarização.

Embora sejam analiticamente trabalhadas entrevistas individuais, com restrições metodológicas a qualquer possibilidade de generalização, considera-se que, uma vez que o discurso trata de uma produção social em determinado tempo e espaço (FIORIN, 2003), há possibilidades de ampliação das análises feitas a partir dos fragmentos discursivos. Assim, quando, com base em um trecho de um depoimento, forem usados termos no plural, coletivos, ou ferramentas linguísticas do gênero dando a entender que a análise ocorre em um sentido mais amplo, a intenção não é a de cometer infrações metodológicas, mas de situar, no nível de análise, o depoimento analisado em um contexto mais amplo.

A organização escolhida para a realização do estudo foi a Faculdade, que, na época de realização do estudo, tinha como meta primarizar os terceirizados que prestavam serviços de vigilância e limpeza dentro de seu campus. As raízes da Faculdade remontam a 1968, quando foi estabelecido um convênio entre duas fundações de região do médio piracicaba, em Minas Gerais, que assegurou a criação e a manutenção de cursos polivalentes da Pontifícia Universidade Católica de Minas Gerais, que desenvolvia atividades na região na época. Os cursos de Licenciatura em Ciências, Letras e Estudos Sociais foram instalados em Itabira, dando origem a uma instituição de ensino superior que precederia a Faculdade. Nos anos 90, essa organização enfrentou grave crise, tendo sido necessário encontrar alternativas que tornassem possível reestruturá-la, mantê-la viva. Foi então que nasceu a Faculdade. Criada no final de 1993 com o objetivo de administrar os cursos superiores de Itabira, constitui uma Instituição sem fins lucrativos, tendo como mantenedores a Prefeitura Municipal de Itabira, a 
Câmara Municipal de Itabira, a Diocese de Itabira e Coronel Fabriciano e a Vale. Hoje oferece os seguintes cursos superiores: Administração, Ciências Contábeis, Turismo, Direito, Engenharia Ambiental, Engenharia de Produção, Sistemas de Informação, Biomedicina, Enfermagem, Farmácia, Fisioterapia, Nutrição, Ciências Biológicas, História, Geografia, Letras, Matemática e Normal Superior. A Faculdade possui mais de 200 profissionais divididos em seu corpo docente, corpo técnico administrativo e empregados terceirizados. Esses últimos correspondiam a quase um quinto do total de empregados na época da pesquisa.

\subsection{Análise das entrevistas}

Nesta seção, os entrevistados apresentam suas representações acerca de diversos elementos do trabalho. As categorias analíticas usadas para o tratamento das entrevistas foram: o trabalho e suas representações; as representações do ambiente profissional; a primarização e a geração de expectativas; as oportunidades de crescimento e suas representações; e as alterações no significado do trabalho com a primarização. A partir delas, pretende-se estabelecer nexos interpretativos com a teoria para o alcance dos objetivos enunciados.

\subsection{O trabalho e suas representações}

Os depoimentos (01), (02) e (03) apresentam considerações sobre o que o trabalho significa para os entrevistados:

(01) [O trabalho é] tudo, né, a pessoa tem que gostar, apesar do salário ser pouco. $\underline{\text { A }}$ gente precisa do emprego para comer, vestir. Tem que trabalhar de cabeça erguida e fazer por merecer. (entrevistado 2)

No fragmento discursivo (01), o entrevistado associa explicitamente a necessidade de o trabalho que se tem ser apreciado, mesmo que mal remunerado (seleção lexical "a pessoa tem que gostar, apesar do salário ser pouco"), o que confirma os argumentos de Saraiva e Silveira (2007) a respeito da valorização do sofrimento no trabalho como requisito para a 
manutenção de uma ética do trabalho, útil ao capitalismo. Como é o meio de satisfazer a necessidades cotidianas ("comer, vestir"), é preciso dedicar-se ao trabalho para preservar o vínculo profissional ("fazer por merecer"). Um aspecto que chama a atenção é o uso explícito da seleção lexical "tem que trabalhar de cabeça erguida". Um implícito pressuposto é o de que o empregado se refere ao fato de que quem tem trabalho possui algo do que se orgulhar, o que não ocorre com um desempregado, por exemplo. A seleção lexical leva a crer que o homem só é digno se for útil, em um sistema que mede o valor do homem pelo que ele produz, e não pelo que ele é como indivíduo.

(02) O trabalho para mim significa alegria; é poder está aí levantando todas as manhãs e saber que você está indo para um local de trabalho e saber que você venceu o mês e você tem o salário para, você sabe [...] é [...] significa muita coisa. Então mais importante para mim [é] que significa você ter durante 30 dias aquele salário porque quantas pessoas não estão desempregadas hoje, quantas pessoas passam por necessidades, ou melhor, quantas pessoas não gostariam de está no meu lugar hoje. então pra mim é muito; como se diz é grandioso poder está trabalhando porque [para] uma pessoa desempregada hoje é muito difícil. Para mim é... não tenho nem como dizer [como] para mim é gratificante. (entrevistado 5)

O mesmo sentimento de gratidão por ter uma ocupação profissional remunerada faz parte do fragmento discursivo (02), explicitamente manifesto no trecho "significa você ter durante 30 dias aquele salário porque quantas pessoas não estão desempregadas hoje". Outro aspecto relevante é que se manifesta uma alusão implícita à luta pela sobrevivência na seleção lexical "você venceu o mês", o que sugere um resultado vitorioso. São nítidas nesses trechos de entrevistas as representações sociais como expressão de um grupo social - os trabalhadores - a respeito da realidade em que vivem, o que sugere a construção coletiva de um sentido para seu cotidiano, o que confirma os argumentos de Xavier (2002). O fragmento discursivo (02), ainda implicitamente, aponta uma espécie de conformismo sobre o trabalho, não importa o seu conteúdo, já que a ameaça do desemprego paira sobre as cabeças dos trabalhadores, o que é confirmado pelo depoimento (03):

(03) O trabalho para mim, o trabalho é o pão de cada dia, é o sustento da minha família então o que tenho que fazer é dedicar ao meu trabalho, é ele que traz o pão. (entrevistado 8)

O fragmento discursivo (03) traduz a ideia de que o trabalho é o meio de conseguir o sustento para a família, é uma dádiva. O implícito pressuposto aqui é que não importa, no primeiro momento, a remuneração, pois trabalhar representa a dignidade do homem. Ainda mostra a importância que tem para o indivíduo estar vinculado a uma organização, sendo para 
a manutenção desse emprego necessária a dedicação ao trabalho, a um contexto profissional que dificilmente se apresenta como neutro ou estritamente produtivo, conforme será discutido na próxima seção.

\title{
4.3 Representações do ambiente profissional
}

O ambiente de trabalho é representado além da esfera profissional propriamente dita, conforme os depoimentos a seguir:

\begin{abstract}
(04) No ambiente $[\ldots]$ que é pra trabalhar [...] é um ambiente bom, mas possível também que você tem que ter bastante dedicação tanto ao trabalho, quanto aos alunos tanto como as pessoas que chegam no prédio também, você tem que estar trabalhando e recebendo as pessoas também, ou seja, você está trabalhando e recebendo bem. Se [alguém] necessitou de algo, você está sempre presente para poder estar ajudando aquelas pessoas. (entrevistado 5)

(05) Já esteve muito ruim, eu sentia muito mal, não estou culpando ninguém e nem estou acusando ninguém, mas já teve ruim. Agora, graças a Deus, está ótimo. Nada a reclamar. (entrevistado 4)

(06) Eu acho aqui na Faculdade eu acho excelente, um ótimo lugar para trabalhar, porque é um lugar descontraído, movimentado, sempre tem coisas diferentes, novidades, torna o ambiente de trabalho mais agradável. (entrevistado 8)
\end{abstract}

Os fragmentos discursivos (04), (05) e (06) tratam do ambiente de trabalho, explicitando que as novidades impedem a sedimentação de rotinas, o que é associado ao contato com estudantes e professores. Silenciam, porém, sobre seu trabalho em si. Pode-se pressupor que, por trabalharem com os chamados 'serviços gerais', tais profissionais não considerem especificamente aspectos relacionados a seu próprio contexto profissional. Por isso, associam-no a um quadro mais amplo, o da faculdade. As representações sociais do ambiente de trabalho constituem medidas sociais da realidade, o que se coaduna com os argumentos de Jodelet (1986), no sentido de que os indivíduos diluem seu ambiente profissional específico em um contexto mais amplo e, possivelmente, mais relevante socialmente. Ao deixar em segundo plano seu trabalho em si, veem-se como parte de um projeto maior e, portanto, socialmente mais relevante. Assim, alguns terceirizados percebem seu trabalho como sendo estimulante, não porque mudam de serviços, mas porque a cada dia conhecem pessoas novas e diferentes, e isso faz com que, no depoimento (07), a rotina do trabalho se torne uma "terapia": 
(07) Para mim [a rotina] é estimulante, é terapia, é tudo. (entrevistado 4)

(08) Sempre estou buscando conhecimento, sempre conhecendo pessoas novas, então [o trabalho] é estimulante. Uma coisa que eu adoro aqui é sempre estar trabalhando com pessoas novas, se torna jovem também. Sempre, os calouros são pessoas jovens, então se estiver com 40 anos vou estar sempre com pessoas jovens. Aí eu chego em casa mais sorridente, você leva aquele espírito jovem para casa, chego lá brinco, se eu vejo uma brincadeira aqui na faculdade, uma brincadeira sadia é lógico, você chega em casa e brinca com a sua esposa também, comenta uma palestra que você viu. $\mathrm{O}$ mais importante no meu serviço é o contato que eu tenho com os alunos e com os superiores, o mais importante é isso aí. (entrevistado 1)

De onde viria o caráter "terapêutico" da rotina profissional do entrevistado 4? A julgar por fragmentos explícitos do texto (08), da convivência com professores e estudantes. É como se o trabalho e sua rotina propriamente dita ficassem ocultos sob a dinâmica social da faculdade. O fragmento (08) é explícito a respeito de que "o mais importante no meu serviço é o contato que eu tenho com os alunos e com os superiores". O contato, e não os objetivos profissionais, ou tampouco sua rotina de trabalho, note-se bem. Nos termos de Saraiva e Provinciali (2002), este posicionamento parece constituir uma forma de resistência em relação à alienação profissional, outra faceta, portanto, das representações sociais. O fragmento discursivo (09) deixa claro, todavia, que a rotina existe:

(09) Não, ele [o trabalho] não é mecânico porque [...] os dias não são os mesmos, [nem] as pessoas, nem todos os dias, [nem] as palavras são as mesmas, no mesmo minuto, no mesmo segundo, né? Tudo tem todo dia [mas] acontece algo diferente, mas nada que fuja do contexto geral de trabalho em se [tratando] da segurança patrimonial. (entrevistado 3)

O entrevistado 3 esclarece que seu trabalho é representado de forma não mecânica por conta das variações cotidianas nos contatos com outras pessoas e situações, mas "Tudo tem todo dia, [mas] acontece algo diferente, mas nada que fuja do contexto geral de trabalho em se [tratando] da segurança patrimonial". Existe um implícito subentendido que a rotina profissional, que se subentende ser regular, padronizada, é "amenizada" pelas interações sociais. Mais uma vez, as representações sociais aparecem como orientadoras de condutas (REIGOTA, 1995). Tais trocas atuam, como será discutido no próximo item, inclusive na criação de expectativas a partir do contexto de primarização. 


\subsection{A primarização e a geração de expectativas}

De acordo com os depoimentos, por conta das mudanças vindouras, muitos empregados se sentem inseguros quanto à sua permanência na empresa onde trabalham. $\mathrm{O}$ medo do desemprego assombra grande parte das pessoas que se sentem acuadas e inseguras:

(10) as pessoas estão meio preocupadas porque não sabem se vão ficar ou não, isso pra mim até afeta um pouquinho o processo de transferência de uma empresa para outra. Então se sentar e conversar eles vão ter mais tranquilidade, um apoio maior, as pessoas vão ser mais responsáveis por aquilo que fazem, vão ter mais conhecimento, vão buscar mais conhecimento, porque não vão estar trabalhando assim numa empresa que me deixava sem informação, eu acredito que também coletivamente vai melhorar. (entrevistado 1 )

(11) Há aí, [para] eu falar verdade, alguns meio apreensivos, com pés atrás, e outros otimistas. (entrevistado 8)

A ausência de informações precisas sobre como ficará a situação dos empregados, no sentido de quem serão "os eleitos", os que permanecerão na Faculdade após a primarização, cria um clima de incerteza e de medo. De certa maneira, os depoimentos (10) e (11) explicitam que o silêncio no processo insere elementos macroeconômicos, como o desemprego estrutural no cotidiano dos terceirizados, o que confirma os argumentos de Druck (2001) a respeito da precarização do trabalho e da tensão constante a que são submetidos os trabalhadores terceirizados. Ao mesmo tempo, porém, parte dos terceirizados vislumbra grandes melhorias: no jeito de trabalhar, na obtenção de conhecimento, no direito a benefícios, na efetivação de uma boa comunicação; em outras palavras, a admissão na faculdade em decorrência do processo de primarização significa melhoria generalizada. $\mathrm{O}$ futuro, assim, é representado como repleto de possibilidades, de outras maneiras de trabalhar, o que indica precariedade no que é atualmente vivenciado. Os depoimentos a seguir são reveladores de como a expectativa da primarização influencia as representações sociais do trabalho:

(12) No meu ponto de vista, no meu pessoal, eu tenho as melhores perspectivas possíveis; tenho porque o sindicato é um sindicato que tem nome, tem voz ativa, não que a Faculdade vai fazer isso ou aquilo outro, não por esse lado. É porque a empresa Faculdade a estrutura dela é legal, tem bons salários, tem uma estrutura

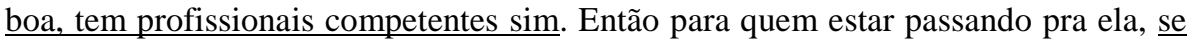
eu realmente for ficar, eu vejo sim tem tudo pra dar certo. (entrevistado 1) 
No fragmento discursivo (12), um dos fatores levantados é a possibilidade de fazer parte, como empregado, de um sindicato atuante, que "tem voz ativa", e que, portanto, vai lutar por melhorias para os que serão primarizados, garantindo igualdade profissional. Nota-se ainda a expectativa da melhoria na remuneração associada a uma valorização profissional implícita dos que permanecerem, já que a Faculdade "tem bons salários", pagos a “profissionais competentes". É ainda desconcertante o contex to de instabilidade vivido pelos profissionais entrevistados enquanto empregados de uma empresa terceirizada (DRUCK; FRANCO, 2007). A seleção lexical "se eu realmente for ficar" encerra esperança e incerteza, pois indica que tudo pode mudar, aparentemente para melhor, se o empregado permanecer na Faculdade. As representações da primarização não se esgotam, porém, nos aspectos de remuneração e competência:

(13) Eu estou torcendo que [...] no caso vai mudar o uniforme [...] os alunos vão ter que respeitar mais os vigias porque a gente vai estar diretamente com eles, eles vão ter que respeitar a gente, a gente também tem que respeitar eles, porque quando $\underline{\text { somos da Contratada }{ }^{4} \text { eles não respeitam muito, mas na Faculdade eles vão ter que }}$ respeitar. (entrevistado 2)

O primeiro elemento que vem à tona com a análise do depoimento (13) é que o uniforme, de mero componente do cotidiano profissional, ascende ao status explícito de artefato simbólico, compondo a representação da primarização. Aparentemente, não basta trabalhar na Faculdade; é preciso também não parecer um empregado terceirizado. Nesse depoimento também é explícita a expectativa de maior respeito ("porque quando somos da Contratada eles não respeitam muito"). Um implícito subentendido é que os terceirizados se sentem discriminados por não serem empregados da Faculdade mas de outra empresa. As representações sociais, nesse sentido, reforçam a ideia de diferença e de discriminação, a partir de artefatos materiais, como o uniforme, passando pelas relações sociais (respeito), o que implica comportamentos específicos ajustados a tais representações (CAMPOS, 2001). Passando a trabalhar na empresa antes contratante, eles não serão excluídos, mas membros de um grupo de empregados que têm os mesmos direitos e deveres.

(14) Primeiro melhora com atendimento ao empregado, segundo uma melhora aos $\underline{\text { salários, }}$ convivência com o superior acho que vai ser bem melhor, uma visão do público lá fora do povo lá fora como se diz é se a gente hoje está trabalhando na Contratada a gente vai trabalhar na Faculdade o pessoal - 'nó!' você está trabalhando na Faculdade? - Melhora empresarial como se diz. (entrevistado 6)

\footnotetext{
${ }^{4}$ Nome fictício para a empresa contratada pela Faculdade na época como terceirizada para a prestação de serviços gerais e de vigilância.
} 
(15) Eu acho que eu vou ficar mais seguro, e vou explicar pra você por quê. Porque agora a gente como você diz, João ${ }^{5}$ vai vir nos acompanhar, vai ter a presença de uma pessoa, que a gente deve fazer reclamações, pedidos, ele vai estar presente diaa-dia com a gente ali, vai ficar muito mais fácil. Costumava algumas coisas a gente precisar e ser atendido um dia depois, tantas horas depois, e aquela coisa tinha que ser solucionada e a gente ter uma pessoa presente, igual João vai estar, vai ser melhor demais. Diversas coisas que a gente pode procurar ele, inclusive conversar com ele, João já é uma pessoa mais sociável. (entrevistado 7)

Nos fragmentos discursivos (14) e (15), a expectativa da primarização é associada, de forma explícita, à melhoria direta na comunicação e no relacionamento entre superiores e subordinados. Um implícito subentendido é que a comunicação e o relacionamento na Contratada não são apreciados, sentindo-se os terceirizados tratados com falta de respeito, um elemento componente de um quadro mais amplo de precarização do trabalho terceirizado, de acordo com Druck (2001). Outro elemento que aparece explicitamente no fragmento (14) é a expectativa a respeito das representações sociais que o público externo terá deles, exterceirizados. De certa forma, ao ingressarem na Faculdade, deixarão de ser socialmente "invisíveis", algo muito importante para um grupo que se sente excluído por conta de ser terceirizado (SANTOS; NOVELINO; NASCIMENTO, 2001). O fim da "invisibilidade" simbólica está ligado às expectativas relacionadas à primarização e às oportunidades criadas a partir dessas expectativas, conforme será discutido a seguir.

\subsection{As oportunidades de crescimento e suas representações}

De maneira geral, os entrevistados esperam uma oportunidade de crescimento na empresa, seja para executar tarefas diferentes das que executam atualmente, seja por meio da expectativa de estudar, via treinamentos, o que constituiria uma forma de valorização.

(16) Acredito na oportunidade de crescimento profissional e pessoal, igual eu tinha falado antes a Faculdade tem a sua estrutura muito boa com certeza ela vai estar desenvolvendo treinamento é conscientizando o empregado para executar os seus serviços da melhor maneira possível, acredito sim pessoalmente e profissionalmente vai ser muito enriquecedor essa mudança. (entrevistado 1)

(17) Eu acho que se a pessoa aqui quiser, eu acho que vai ter uma oportunidade para todos que quiser[em] mesmo, eu acho que vai ter desempenhar um papel

\footnotetext{
${ }^{5}$ Nome fictício para o empregado que, na época da pesquisa, centralizava a comunicação com os empregados terceirizados na Faculdade.
} 
trabalhando direitinho aí atendendo a Faculdade eu creio que vai ter uma coisa de boa aí pra ela futuramente. (entrevistado 2)

(18) Olha esperamos que sim porque todo mundo tem oportunidade uma vez. Quando a pessoa estuda, ela quer crescer e ela quer ter oportunidade eu creio que eles vão estar analisando o crescimento também. (entrevistado 5)

Os depoimentos (16), (17) e (18) manifestam expectativas explícitas quanto a receber qualificação para executar suas tarefas, bem como outros treinamentos básicos, como de informática. Tendo em vista o baixo nível de escolaridade de grande parte dos terceirizados, eles esperam também cursos de alfabetização, embora eles não mencionem explicitamente tal posicionamento. Embora almejem o que foi citado, pelos depoimentos nota-se que está claro que, para alcançar esse crescimento pessoal e profissional, é necessário dedicação de cada um para se manter empregável ("eu acho que vai ter desempenhar um papel trabalhando direitinho aí atendendo a Faculdade eu creio que vai ter uma coisa de boa aí pra ela futuramente"), ou seja, reunir permanentemente as competências demandadas para atender às contínuas exigências do mercado de trabalho, o que confirma parte dos achados de Caputo e Palumbo (2005) sobre o setor têxtil.

(19) [Eu espero] mais segurança no trabalho, mais benefícios. E eu quero ter a oportunidade de crescer mais, porque eu tenho as minhas filhas futuramente, se Deus me ajudar [...] estudando na Faculdade. O que eu fizer de bom aqui para você, com certeza, no futuro eu terei alguma coisa que será de agrado para meus filhos. Eu penso mais nos meus filhos mesmo. (entrevistado 7)

No depoimento (19), é invocada explicitamente a oportunidade de crescimento, associada, de forma implícita, à dedicação ao trabalho para conseguir os benefícios não só para ele enquanto empregado, é associada também à família (seleções lexicais "eu tenho as minhas filhas futuramente [...] estudando na Faculdade" e "o que eu fizer de bom aqui para você com certeza no futuro eu terei alguma coisa que será de agrado para meus filhos"). Esse depoimento reitera a representação de uma ética associada ao trabalho, uma valorização moral da atividade laborativa, o que está de acordo com o que argumentam Lima (1988), Saraiva e Provinciali (2002) e Saraiva e Silveira (2007).

É interessante notar que os entrevistados associam suas representações com relação ao trabalho à ideia de permanência na Faculdade, de estabilidade no emprego, mas não na perspectiva tradicional, de tempo de serviço. De certa forma, esse dado é um contraponto direto à instabilidade da terceirização apontada por Druck (2001) e Druck e Franco (2007). O que se representa é que a estabilidade e um futuro são possíveis a partir da dedicação e competência no trabalho: 
(20) É depende de cada um porque se eu executo um bom serviço eu vou ter com certeza os olhares do meu supervisor vão [...] [continuar] com aquele empregado que está sempre executando um bom serviço, ele vai continuar [...] [se] ele fizer corpo mole, deixar alguma coisa a desejar, não evoluir, [não se] adequar às situações que estão ao seu redor, com certeza tem hoje profissional no mercado e com certeza ele será substituído, isso não só aqui mas em qualquer empresa, hoje é a mão-de-obra tem que ser 'super'. (entrevistado 1)

(21) Isso vai depender do meu desempenho na empresa. Se eu não tiver desempenho, eu não tenho estabilidade nenhuma. (entrevistado 6)

Sem dúvida, o comprometimento e a geração de resultados influenciam a permanência no ambiente profissional. Mas fazem parte dessa equação outros fatores, como a própria rentabilidade do negócio, o nível de competição enfrentado, a questão dos custos, da margem de lucro etc. Os depoimentos (20) e (21) atribuem aos empregados a responsabilidade pela permanência, o que só pode ser encarado como muito oportuno ao projeto organizacional (CARMO, 1997). A instabilidade, nessa linha de raciocínio, não se deve a relações de trabalho precárias mas ao desempenho do empregado em suas funções cotidianas. É esse desempenho que pode garantir (ou não) a permanência. A empregabilidade, assim, não depende apenas dos empregados, mas da articulação de uma série de fatores, compartilhados entre organização e empregado. Condicionar a permanência no emprego ao esforço de apenas uma das partes é uma distorção ideológica que beneficia um dos lados em detrimento direto da outra parte, o que se dá, em parte, a partir das representações sociais do trabalho.

\subsection{Alterações no significado do trabalho com a primarização}

Embora os terceirizados esperem melhorias com a primarização, não percebem mudanças expressivas no que o trabalho representa para eles, conforme os depoimentos a seguir:

(22) Ah mudar eu creio que vai mudar uma coisa e outra, né, mas é trabalho, faz parte da vida da gente [...] (entrevistado 2)

(23) Lógico que será a mesma coisa, mesmo depois de aposentada [a] mesma coisa. (entrevista 4) 
O fragmento discursivo (22) é explícito quanto ao fato de que a mudança é esperada, conforme a seleção lexical "mudar eu creio que vai mudar uma coisa e outra". Existe, todavia, um implícito subentendido de que o trabalho, na essência, não deve se alterar significativamente, uma visão que sugere certa inexorabilidade do trabalho na participação da vida do trabalhador A seleção lexical "mas é trabalho, faz parte da vida da gente", denota semanticamente que a atividade profissional e sua carga de esforço (SARAIVA; SILVEIRA, 2007) constituem algo intrínseco da vida de empregados como o entrevistado. O fragmento discursivo (23) é ainda mais claro a esse respeito, pois explicita que o trabalho constituirá sempre "a mesma coisa, mesmo depois de aposentada [é a] mesma coisa".

A análise dos dados permitiu identificar representações sociais variadas sobre as expectativas associadas ao processo de primarização. Do trabalho, passando pelo ambiente profissional, pela primarização, pelas oportunidades de crescimento, ao significado do trabalho, as representações sociais identificadas conferem um caráter positivo à primarização, mesmo que se saiba, de antemão, que é um processo no qual nem todos os empregados serão incluídos. Essa perspectiva favorável diz muito sobre o contexto atualmente vivenciado por eles como empregados terceirizados, pois, se tudo tende a melhorar, é porque o contexto atual não é apreciado. As representações sociais, nesse sentido, constituem uma possibilidade interessante aos gestores que atentarem para que elementos não objetivos afetem sobremaneira o contexto do trabalho, ainda que não façam parte, a rigor, das ferramentas empresariais, conforme será discutido a seguir.

\section{CONSIDERAÇÕES FINAIS}

Neste artigo, o objetivo foi identificar como a expectativa de primarização influencia as representações sociais dos empregados terceirizados sobre o trabalho. Para tanto, foi conduzida uma pesquisa qualitativa embasada na teoria das representações sociais, em uma instituição de ensino superior, prestes a primarizar os serviços de vigilância e de limpeza na época do estudo. No total, oito empregados terceirizados foram entrevistados com base em um roteiro semiestruturado, abordando diversos aspectos relacionados às representações sociais naquele momento específico. As entrevistas foram integralmente gravadas e transcritas como meio de assegurar maior fidedignidade do material coletado e, posteriormente, tratadas com base na análise francesa do discurso. As conclusões deste estudo pedem cautela no 
tocante à generalização, uma vez que restringem sua aplicabilidade a um contexto específico.

Os principais resultados dão margem a diversas considerações a respeito de como a expectativa da primarização influencia as representações sociais sobre o trabalho. $\mathrm{O}$ significado do trabalho para os terceirizados está ligado ao fato de representar, inicialmente, o sustento para a família, a dignidade do homem. Não importa qual o trabalho e nem o valor recebido para executar os serviços, o importante é trabalhar - é isso que dignifica o homem. Embora o trabalho seja representado dessa forma, os entrevistados almejam melhoria na condição de trabalho com o processo de primarização: mais respeito profissional mediante melhor relacionamento entre superiores e subordinados, melhoria na comunicação, melhoria salarial (o que se estende aos benefícios), oportunidades de crescimento pessoal e profissional, enfim, suas expectativas giram em torno de serem "iguais" aos empregados da Faculdade. De certa forma, o desejo é o de "serem vistos", uma vez que trabalhadores de determinadas categorias profissionais parecem "invisíveis", especialmente se atuam na precária condição de terceirizados.

Tais expectativas alteram as representações sociais do trabalho, que passa a ser associado não apenas à fadiga e ao sustento para família. O trabalho também é percebido como prazeroso e importante para o indivíduo, no sentido de que ele se sente contribuindo para o alcance dos objetivos organizacionais, participando efetivamente do cumprimento de suas metas e que a empresa o reconhece e valoriza tal participação. É lícito supor que tal posicionamento se deva também ao fato de que o comprometimento com o trabalho pode ser uma variável decisiva para a seleção dos que serão primarizados.

Outro ponto importante que pode ser levado em consideração é que, conforme os depoimentos dos terceirizados, há expectativas de grandes melhorias ao serem contratados pela Faculdade. Essas melhorias, contudo, não dependem exclusivamente da organização, podendo depender de sua condição econômico-financeira, da concorrência e de outras variáveis além do processo de contratação propriamente dita. Assim, a possibilidade de que esses terceirizados se frustrem é elevada, pois a primarização não significa perfeição, sendo, antes de qualquer coisa, uma ferramenta empresarial. A não-efetivação do que se espera pode alterar as atualmente positivas representações sociais do trabalho sobre o processo, fazendo com que retornem à noção anterior do trabalho apenas como fator de subsistência, ou seja, de que só se trabalha porque dinheiro é necessário para sobreviver. Isso pode acarretar desdobramentos tão negativos quanto os da terceirização propriamente ditos.

Ao representar a primarização e seus desdobramentos, os empregados entrevistados fazem mais do que apenas interpretar o contexto que conseguem perceber mais imediatamente 
a seu redor. Eles dão pistas muito interessantes a respeito de por que e para que percebem as coisas de uma dada forma. Pelos elementos disponíveis na pesquisa, pôde-se perceber que a precariedade do trabalho em um contexto terceirizado os leva a encarar, com certo exagero, os benefícios de virem a se tornarem empregados formais da organização que hoje subcontrata seus serviços. A partir da expectativa de abandonar as condições precárias e instáveis de trabalho em que hoje se encontram, eles projetam um futuro em que o trabalho será necessariamente melhor porque deixarão de ser "terceiros". O fato de passarem a ser detentores de direitos trabalhistas de que hoje dispõem muito restritamente os leva a esperar melhorias expressivas no trabalho que hoje executam, quando não há indicadores de que isso vá acontecer, considerando o papel de apoio que suas atividades têm no contexto do negócio da organização, a educação.

As principais implicações deste estudo dizem respeito ao quanto as representações sociais são formas de ver - e, também, de não ver a realidade ao redor. À medida que projetam em um futuro promissor suas possibilidades de realização, os empregados entrevistados põem, em um segundo plano, a precariedade de suas vigentes relações sócioprofissionais. A promessa de uma outra vida profissional, cercada de recompensas para os que se esforçarem para tanto, paira como uma retribuição justa pelo duro trabalho como empregado terceirizado. A redenção que virá com a contratação como empregados efetivos, que os livrará de um quadro desfavorável do qual hoje não conseguem escapar, constituirá uma compensação por todo o esforço despendido. Tantas expectativas associadas à primarização surpreendem e, ao mesmo tempo, preocupam, pois não há meios de que se viabilizem com a efetivação desses profissionais terceirizados. Mas não deixa de ser útil à lógica do sistema que tal esperança exista, pois ela implica competição, dedicação e comprometimento com uma realidade da qual apenas alguns, os vencedores, participarão.

O mesmo movimento capitalista que tornaria as empresas competitivas por meio da terceirização agora as aproxima da primarização. Ao se depararem com os efeitos dos custos da precarização do trabalho promovida pela terceirização, as organizações voltaram a verticalizar o processo produtivo, primarizando o que estava nas mãos de outras organizações. Esse processo, que considera apenas em um segundo momento os trabalhadores e suas necessidades, tem na acumulação capitalista seu principal foco. Terceirizar ou primarizar as atividades produtivas, portanto, é só parte de uma decisão mais ampla sobre estratégia organizacional. Este estudo demonstra, todavia, que as representações sociais têm influência sobre a organização e suas práticas, o que merece ser objeto de maior atenção por parte dos gestores a fim de que lidem, de forma mais adequada, com as pessoas no ambiente. 
Referências

ALBORNOZ, S. O que é trabalho. São Paulo: Brasiliense, 1986.

BAKHTIN, M. (Voloshinov). Marxismo e filosofia da linguagem. 8. ed. São Paulo: Hucitec, 2006.

CAMPOS, P. H. F. Quando a exclusão se torna objeto de representação social. In: MOREIRA, A. S. P. (Org.). Representações sociais: Teoria e prática. João Pessoa: Universitária, 2001.

CAPUTO, A. C.; PALUMBO, M. Manufacturing re-insourcing in the textile industry: A case study. Industrial management \& data systems, Bingley, v. 105, n. 2, p.193-207, 2005.

CARMO, P. S. A ideologia do trabalho. São Paulo: Moderna, 1997.

DRUCK, M. G.; FRANCO, T. (Org.). A perda da razão social do trabalho. São Paulo: Boitempo, 2007.

DRUCK, M. G. Terceirização: (des)fordizando a fábrica. São Paulo: Boitempo, 2001.

DURKHEIM, É. O suicídio. Rio de Janeiro: Zahar, 1982.

ESLAVA ALBARRACÍN, D. G.; ALMEIDA, M. C. P. Representaciones sociales de salud y enfermedad: Investigando el estado del arte. Ciencia y Enfermería, Concepcion, v. 8, n. 2, p.59-72, Dic. 2002.

FARR, R. M. Representações sociais: a teoria e sua história. In: GUARESCHI, P.; JOVCHELOVITCH, S. (Org.). Textos em representações sociais. Petrópolis: Vozes, 1994.

FIORIN, J. L. Linguagem e ideologia. 7. ed. São Paulo: Ática, 2003.

FROMM, E. O conceito marxista do homem. Rio de Janeiro: Guanabara Koogan, 1983.

HERZLICH, C. A problemática da representação social e sua utilidade no campo da doença. Rio de Janeiro: Physis, v. 1, n. 2, p.23-36, 1991.

JODELET, D. La representación social: Fenômeno, concepto e teoria. In: MOSCOVICI, S. (Org). Psicología social. Buenos Aires: Paidós, 1986.

KUPSTAS, M. (Org). Trabalho. São Paulo: Moderna, 1997.

LIMA, M. E. A. O significado do trabalho humano. In: CARVALHO, A. O. (Org.). Administração contemporânea: Algumas reflexões. Belo Horizonte: UFMG, 1988.

MAGNANI, J. G. Discurso e representação, ou de como os baloma de kiriwina podem encarnar-se nas atuais pesquisas. In: CARDOSO, R. (Org.). Aventura antropológica. Rio de Janeiro: Paz e Terra, 1986.

MAINGUENEAU, D. Termos-chave da análise do discurso. Belo Horizonte: UFMG, 1998. 
MINAYO, M. C. S. Fala galera: juventude, violência e cidadania na cidade do Rio de Janeiro. Rio de Janeiro: Garamond, 1999.

MINAYO, M. C. S. (Org.). Pesquisa Social: teoria, método e criatividade. 6. ed. Petrópolis: Vozes, 1996.

MORIN, E. M. Os sentidos do trabalho. Revista de Administração de Empresas, São Paulo, v. 41, n. 3, p.8-19, jul./set. 2001.

MOSCOVICI, S. On social representations. In: FORGAS, J. P. (Org.). Social cognitions perspectives on everyday understanding. New York: Academic Press, 1981.

MOSCOVICI, S. Prefácio. In: GUARESCHI, P.; JOVCHELOVITCH, S. (Org.). Textos em representações sociais. Petrópolis: Vozes, 1995.

MOSCOVICI, S. Representação social da psicanálise. Rio de Janeiro: Zahar, 1978.

MOSCOVICI, S. Social representations. Cambridge: Cambridge University Press, 1984.

OLIVEIRA, C. R. História do trabalho. São Paulo: Ática, 1995.

OLIVEIRA, F. O.; WERBA, G. C. Representações sociais. In: JACQUES, M. G. C.; STREY, M. N.; BERNARDES, M. G.; GUARESCHI. P. A.; CARLOS, S. A.; FONSECA, T. M. G. (Org.). Psicologia social contemporânea. 4. ed. Petrópolis: Vozes, 1998.

REIGOTA, M. Meio ambiente e representação social. São Paulo: Cortez, 1995.

SANTOS, M. F. S.; NOVELINO, A. M.; NASCIMENTO, A. P. O mito da maternidade: Discurso tradicional sob roupagem modernizante? In: MOREIRA, A. S. P. (Org.).

Representações sociais: Teoria e prática. João Pessoa: Universitária, 2001.

SARAIVA, L. A. S.; PROVINCIALI, V. L. N. Desdobramentos do taylorismo no setor têxtil - Um caso, várias reflexões. Caderno de Pesquisas em Administração, São Paulo, v. 9, n. 1, p.19-33, jan./mar. 2002.

SARAIVA, L. A. S.; SILVEIRA, L. G. A. Representações sociais do trabalho entre profissionais de um hospital de Minas Gerais. Revista de Gestão USP, São Paulo, v. 14, n. 2, p.77-91, abr./jun. 2007.

SPINK, M. J. O conhecimento no cotidiano: As representações sociais na perspectiva da psicologia social. São Paulo: Brasiliense 1995.

XAVIER, R. Representação social e ideologia: Conceitos intercambiáveis? Psicologia \& Sociedade, Porto Alegre, v. 14, n. 2, p.18-47, jul./dez. 2002. 